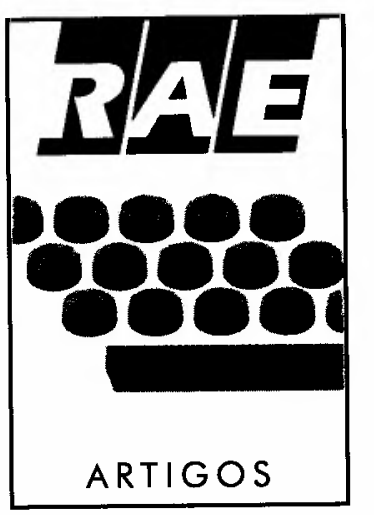

\title{
GERENCIAMENTO DA \\ QUALIDADE TOTAL: UMA REVISÃO CRÍTICA
}

*Tomaz Wood Jr. **Flávio Torres Urdan

Uma pesquisa com base na produção mais recente sobre o assunto revela crescente insatisfação com os resultados conseguidos e indica possíveis alternativas.

A survey based on the most recent publications on TQM shows increasing signals of unsatisfaction among practioners and indicates alternatives for future developments.

\section{PALAVRAS-CHAVE:}

Gerenciamento da qualidade total, mudança organizacional, análise organizacional.

\section{KEY WORDS:}

Total quality management, organizational change, organizational analysis.

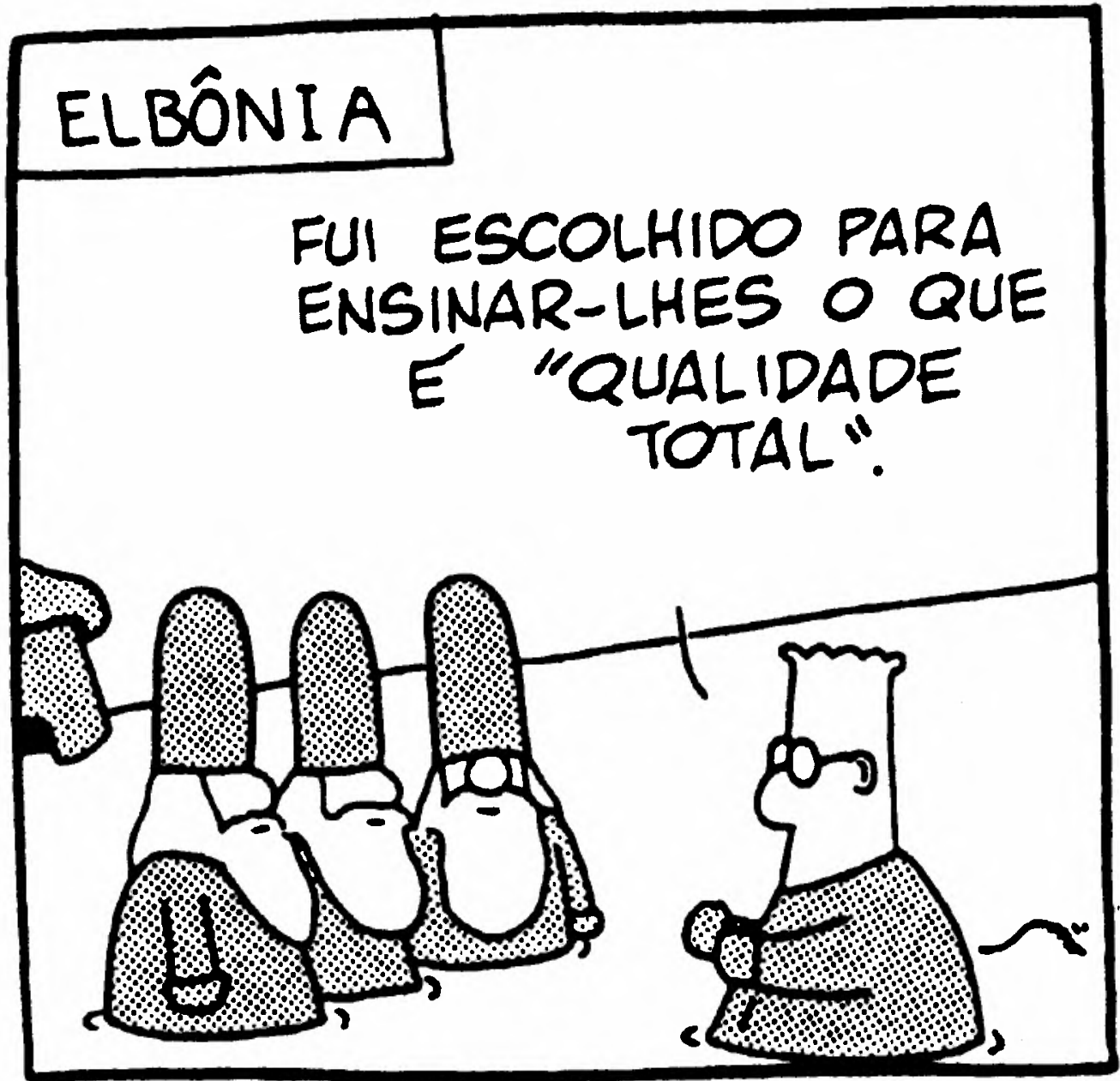

"Doutorando em Administração de Empresas na EAESP/FGV e Professor Universitário.

**Mestre em Administração de Empresas pela EAESP/FGV Consultor de Empresas e Professor Universitário. 
O Gerenciamento da Qualidade Total (TQM) passa por um momento de amadurecimento e questionamento. Em razão disso, este trabalho procura formular uma visão crítica do assunto e fornecer ao leitor um quadro geral do tema e de sua inserção na complexidade organizacional. Os objetivos dos autores são os seguintes:

- mostrar as tendências e preocupações mais atuais divulgadas através de livros, artigos e outros meios, proporcionando ao leitor um quadro geral do assunto;

- discutir limitações e problemas práticos de aplicação;

- apontar abordagens complementares e alternativas e suas interações com TQM.

Observe-se que existe material abundante sobre o assunto, o que reflete sua importância e interesse. No entanto, quase não há produção acadêmica abordando-o, podendo-se afirmar que existe certo preconceito e que os poucos estudiosos
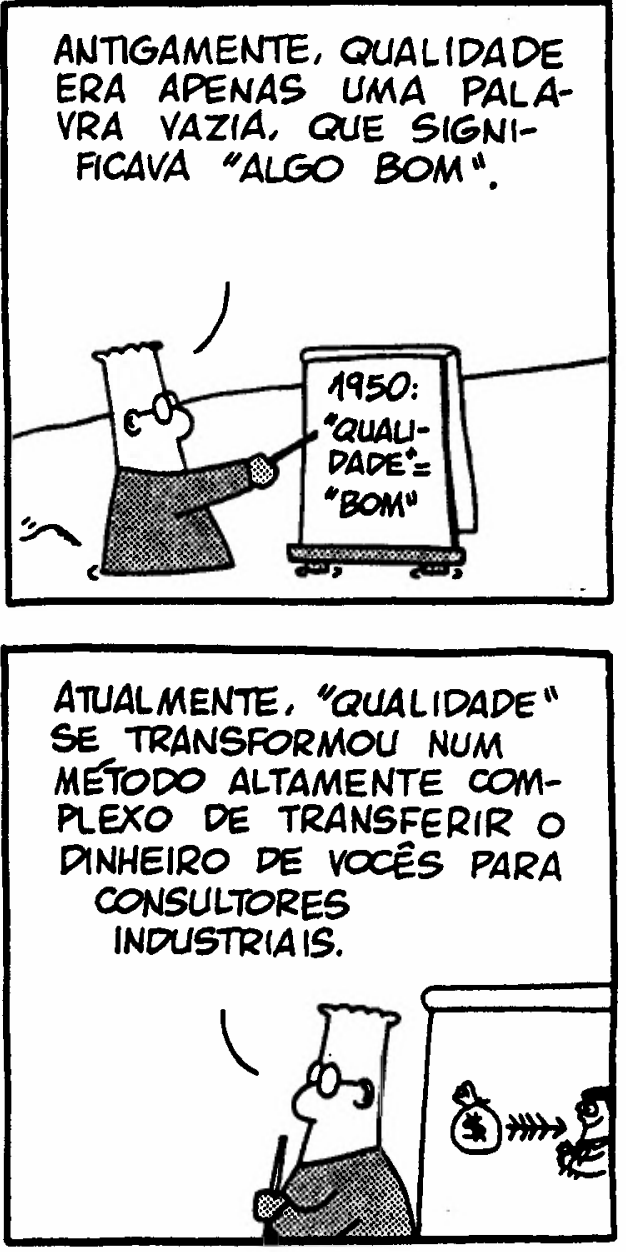

que tratam do assunto costumam fazê-lo de forma crítica.

O artigo é de caráter limitado, ainda que o universo considerado, acreditamos, seja suficiente para introduzir o assunto e analisar alguns pontos essenciais, sua amplitude e implicações bem pediriam análise de maior fôlego.

Inicialmente, apresenta-se um quadro analítico ligando qualidade aos conceitos de competitividade e mudança organizacional. A seguir, procura-se recuperar aspectos históricos do desenvolvimento do conceito de TQM. Também são apresentadas as tendências atuais e as críticas mais comuns encontradas. Discutem-se limitações, possíveis soluções para essas limitações e abordagens alternativas. As seções seguintes são dedicadas às questões correlatas da reengenharia e do sistema ISO. Duas seções são destinadas à discussão relativamente recente da qualidade aplicada a setores não-industriais. Na conclusão, aborda-se o ciclo de inovações gerenciais.

\section{CRIANDO UM QUADRO ANALÍTICO}

Um discurso corrente dá conta que o movimento da qualidade foi a redenção do Japão do pós-guerra e deve ser uma prioridade nacional. Implantar um bom programa de qualidade seria suficiente para aumentar a competitividade, os lucros e garantir a perenidade dos negócios. A felicidade e a prosperidade ao alcance das mãos!

Para evitar esse tipo de tratamento simplista, propomos, então, que o tema TQM seja aproximado através de um quadro de referências decomposto em dois níveis: $\mathrm{o}$ primeiro, mais amplo, refere-se à competitividade nacional; o segundo, no nível intra-organizacional, refere-se à questão das mudanças da organização do trabalho e dos paradigmas gerenciais.

Tomemos o primeiro nível, utilizando a abordagem de Porter ${ }^{1}$. Para ele, a condição de sucesso de uma empresa está na capacidade de inovação, tomada em sentido amplo, englobando da tecnologia às novas formas de gerenciamento. $\mathrm{O}$ autor propõe um modelo de quatro variáveis, interdependentes e interatuantes, para analisar o problema. São elas: a posição de uma nação em termos de infra-estrutura, educação, trabalho, recursos etc.; a existência de indústrias fornecedoras ca-
1. PORTER, Michael A. The competitive advantage of nations. New York: Free, 1990. $855 \mathrm{p}$. 
Figura 1

Empresa como coleção de processos

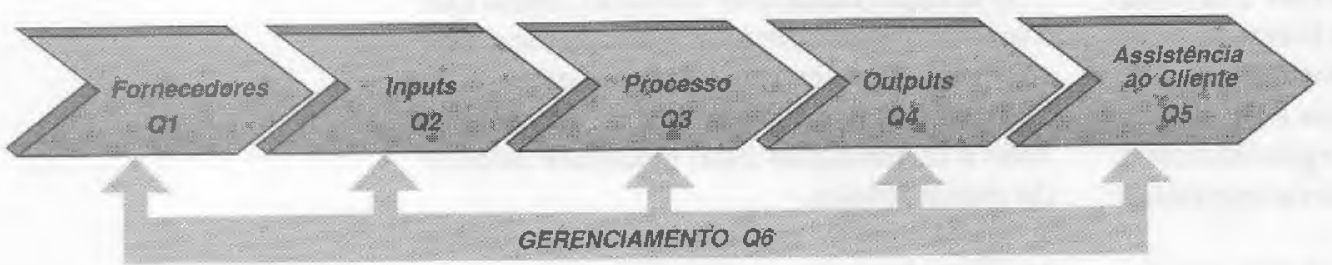

tais e conceitos gerenciais, mas nunca perdeu um certo ranço tecnicista, surgindo daí grandes limitações. Apesar de se pretender um instrumento de mudança podendo sê-lo, dentro de certos limites - não tem alcance sobre a complexa rede de as-

pazes e competidores fortes; as condições relacionadas à estrutura econômica e empresarial do país e a existência de um mercado exigente e sofisticado. Percebese que no modelo de Porter a qualidade, no sentido amplo, permeia todos os elementos. Deve ser entendida como variável endógena do sistema, sem predominância sobre as demais.

Mas o tema tratado não é a qualidade em geral, mas o conceito de Gerenciamento da Qualidade Total, o que nos leva ao segundo núvel, mais restrito, de análise. Aqui propomos que TQM insere-se no quadro das mudanças organizacionais hoje em curso, o que o inclui num amplo movimento de profundas alterações estratégicas, culturais e estruturais.

Desse contexto, origina-se um ponto de tensão para a aplicação do TQM. Originalmente uma coleção de técnicas e metodologias dc engenharia e estatística, a onda da qualidade assimilou, ao longo do tempo, alguns elementos comportamen- pectos relacionados à mudança organizacional.

Mesmo dentro do quadro funcionalista, suas proposições soam como oportunistas ou ingênuas, diante do estado da arte do assunto. Assim, corre o risco de permanecer como conhecimento e linguagem de gueto, ocupando áreas específicas dentro de empresas, mídia própria etc.

\section{O QUE É, AFINAL, TQM?}

Harari ${ }^{2}$ argumenta que, em virtude da proliferação de definiçōes, teorias e programas, é difícil especificar com precisão o significado de TQM.

Comecemos, então, por definir qualidade. A maior parte dos conceitos foi curhada pelos chamados gurus da qualidade. Essas definições, embora tenham variações em amplitude e profundidade, giram sempre em torno dos conceitos de conformidade, adequação ao uso e satisfação do cliente. Um modo alternativo de entender
2. HARARI, Oren. Ten reasons why TQM doesn't work. Management Review, Saranac Lake, v. 82 , ก. 1, p. 33-8, Jan. 1993.

\section{Quadro 1 \\ O conceito de TQM: elementos e ferramentas}

TQM: elementos básicos

- visão organizacional

- eliminaȩãa de barteiras:

- comunicação;

- avaliação continnua:

TQM: ferramentas e técnicas

- diagramas de causa e efeito;

- coleta de dados e follhas de verificação;

- fluxogramas e esfedo de inputs e oufputs:

- análise do fluxo de trabalho;

- ciclo de Deming;

- análise do campo de forças:

- fixação de objetivos;

- quadro de programação de đecisões;

- quality function deployment;

- auditoria;

- benchmarking:

- análise de falhas e efeitos:
- melhoria contínua;

- relacionamentos cliente/fornecedor;

- empowermen do trabalhador;

- treinamento.

- brainstorming:

- método Delphi;

- nominal group techuiques:

- círculos de quálidade;

- qualidade de serviço;

- métodos estatísticos e de amostragem;

- gráficos de controle;

- projeto de experimentos;

- operação evolucionária:

- análise de Pareto;

- foolprosfing:

- quén - o quế- quando por quế- como? 


\section{Figura 2} Elementos do Hoshin Kanri

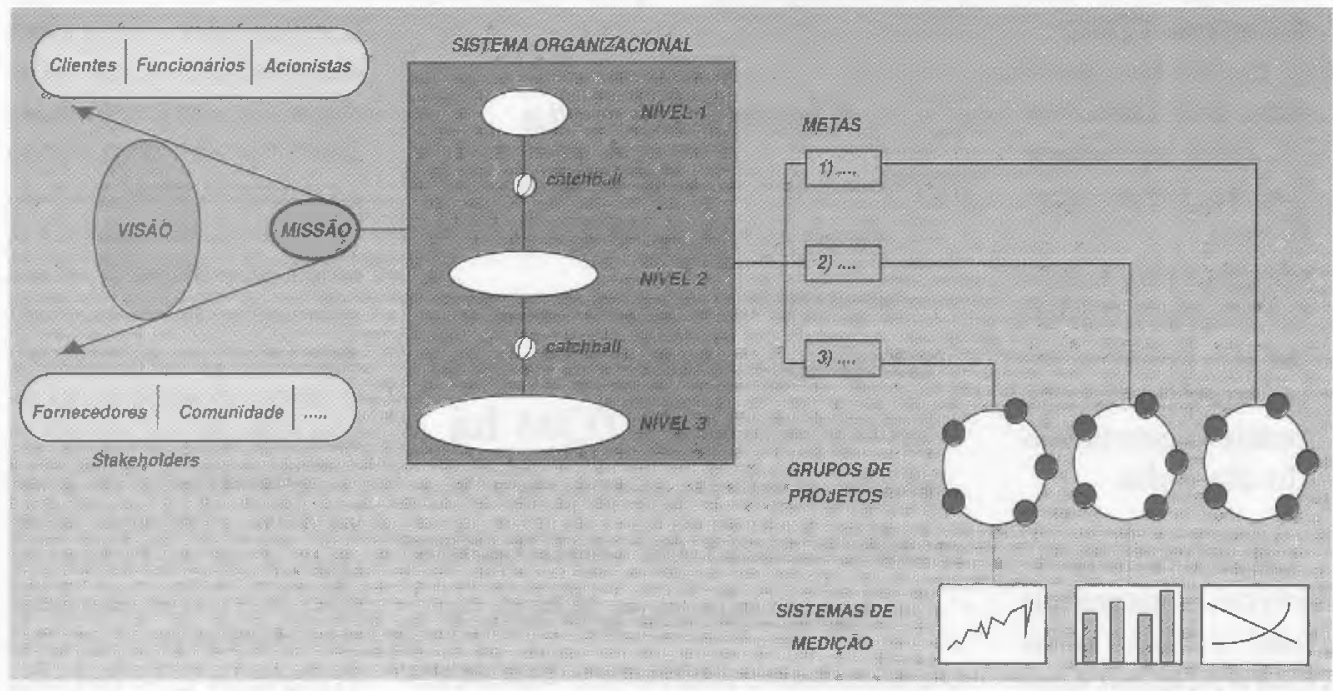

o assunto é pensá-lo de forma sistêmica, como a interaçấo de três variáveis: o produto, o cliente e o uso. É da dinâmica dessa interação, na multiplicidade de possibilidades existentes, que nasce a idéia de qualidade.

Para vincular qualidade a TQM, devese recorrer à visão da empresa como processo - ou coleção de processos. Um modelo assim formulado é o dos 5Q's (ver figura 1).

Vejamos, agora, algumas definições de TQM:

- Becker ${ }^{3}$ define Qualidade Total (QT) como um sistema administrativo orientado para pessoas cujo objetivo é o incremento contínuo da satisfação do cliente a custos reais decrescentes. QT é uma abordagem sistêmica e parte de uma estratégia de alto nível; ela funciona horizontalmente através de funções e departamentos, envolve todos os funcionários, fornecedores e clientes da empresa. QT enfatiza o aprendizado e a adaptação às mudanças como fatox-chave para o sucesso organizacional;

- Mears ${ }^{4}$ define TQM como um sistema permanente e de longo prazo, voltado para alcançar a satisfação do cliente através da melhoria contínua da qualidade dos serviços e produtos da empresa;

- para Aggarwal5, TQM é uma filosofia para conquistar a confiança do cliente e garantir a rentabilidade de longo prazo da empresa;
- Brocka e Brocka ${ }^{6}$, a partir de outra persde TQM apresentando seus elementos básicos e as ferramentas e técnicas que podem ser empregadas nos programas de implementação de QT, conforme o quadro 1.

\section{ASPECTOS HISTÓRICOS - AS ESCOLAS DA QUALIDADE}

Segundo Schneider ${ }^{7}$, a idéia de prover produtos de qualidade que sejam adequados aos desejos do consumidor não é nova. Antes da Revolução Industrial os artesãos já o faziam, interagindo diretamente com os consumidores.

O surgimento do TQM pode ser relacionado ao desenvolvimento dos modelos gerenciais e do próprio movimento da qualidade e explicado por uma seqüência didática de seis momentos, alguns quase simultâneos:

- o da inspeção, o foco no controle do produto final, associado ao desenvolvimento do sistema de produção e consumo em massa;

- o surgimento do foco no processo, com uma coleção de técnicas estatísticas;

- a integração destas técnicas num modelo gerencial restrito - o Controle da Qualidade Total (TQC);

- a incorporação de elementos comportamentais e novas práticas gerenciais associadas ao acirramento da competição pectiva, procuram esclarecer o conceito
3. BECKER, Selwyn W. TQM coes work: ten reasons why misguided attempts fail (discussion of 0. Harari's Jan. 1993 article). Management Review. Saranac Lake, v. 82, n. 5, p. 30, May 1993

4. MEARS, Peter. How to stop taiking about, and begin progress toward, total quality management. Business Horizons, Greenwich, v. 36, p. 11-4, May/ June 1993.

5. AGGARWAL, Sumer. A quick guide to total quality management. Business Harizons, Greenwich, v. 36, p. 66-8, May! June 1993.

6. BROCKA, BrUCe, BROCKA, M. Suzanne. Quality management: implementing the best ideas of the masters. Homewood: Business One Irwin, 1992. $408 \mathrm{p}$.

7. SCHNEIDER, Alan J. TQM and the financial function. Journal of Business Strategy, Boston, v. 13, n. 5, p. 21-5, Sept./Oct. 1992. 
8. BROCKA, Bruce, BROCKA, M. Suzanne. Op. cit.

9. DOBYNS, Lloyd, CRAWFORD-MASON, Clare. Quality or else. New York: Houghton Mifflin Company, 1991. $309 \mathrm{p}$.

10. DEMING, W. Edward. Out of the crisis. Cambridge, Mass.: MIT, 1986. $507 \mathrm{p}$.

11. CROSBY, Philip B. Quality is free. New York: McGraw-Hill, 1990.

12. JURAN, Joseph M. Quality Control Handbook. New York: McGraw-Hill, 1983. entre empresas, ao início da flexibilização da produção e ao aumento da fragmentação dos mercados. Consagração do termo TQM;

- a expansão para fora das fábricas, no setor serviços $\mathbf{e}$ nas empresas públicas;

- tendência de transformação profunda do modelo e/ ou sua difusão nas práticas gerenciais do dia-a-dia.

Um sistema significativo do momento atual vivido pelo TQM é o Hoshin Kanri - ou Policy Deployment -, que busca unir os elementos essenciais e os diversos níveis dos processos de planejamento e ação estratégicos com as várias metodologias e conceitos ligados ao movimento da qualidade (ver figura 2 ).

\section{OS GURUS DA QUALIDADE}

A maior parte dos princípios e práticas que suportam o TQM deriva de contribuições de um grupo restrito de estudiosos. Tidos como mestres, ou gurus, o conhecimento de seu trabalho é requisito para qualquer esforço visando a compreender e implementar o TQM nas organizações. Brocka e Brocka ${ }^{8}$ e Dobyns e CrawfordMason $^{9}$ descrevem aspectos centrais do pensamento de Philip Crosby, Edward Deming, Armand Feigenbaun, Kaoro Ishikawa e Joseph Juran.

Deming talvez tenha sido o mais celebrado guru da qualidade. Comparado com os demais mestres, cujas orientações são de caráter marcadamente prático, pode ser considerado um filósofo, um pregador em busca de discípulos. Diz-se que muitos dos que adotam suas idéias o fazem com devoção quase religiosa. Para eles, o método de Deming não somente aprimora a qualidade de bens e serviços mas é capaz de fazer suas vidas melhores (!). Além de fi- losóficas, as prescrições de Deming têm caráter revolucionário, pois subentendem profundas transformações no relacionamento entre a empresa e seus clientes, fornecedores e empregados. Deming alertava sobre as dificuldades e o longo tempo necessário à implementação de suas recomendações. Seu método possui catorze pontos, descritos no livro Out of the crisis ${ }^{10}$.

Quality is free ${ }^{11}$, de Crosby, vendeu mais que dois milhões de cópias. Formado dentro de empresas, ao contrário dos demais mestres, considera-se um pensador de negócios pragmático e não um guru da qualidade. Crosby criou a concepção zero defect e popularizou o conceito de fazer certo da primeira vez. Teria chegado a eles em virtude da insatisfação com o que Deming e Juran ensinavam. Para Crosby, a teoria de Deming fundamenta-se na estatística, que poucos são capazes de compreender e que pouco contribui para o gerenciamento cotidiano da qualidade nas empresas. Deming, replicando, negava que o controle estatístico da qualidade fosse o fator preponderante para o sucesso de uma organização. Além disso, nunca escondeu sua desconsideração pelos programas de qualidade ministrados por Crosby. Estes, coincidentemente, também se baseiavam em catorze pontos. Crosby é o único entre os mestres que considera a qualidade um conceito de razoável simplicidade.

Juran contribuiu decisivamente no movimento japonês em prol da qualidade. Segundo ele, a administração da qualidade compreende três processos básicos: planejamento, controle e melhoria - a trilogia de Juran ${ }^{12}$. Para Juran, as abordagens conceituais necessárias ao gerenciamento dos três processos são similarares àquelas empregadas na administração financeira. Assim, enquanto Deming afirma que a administração da qualidade requer transfor- 


\section{Quadro 2 \\ TQM: problemas de aplicação}

- criaçäo de uma burocraçia interna paralela:

- foco na imagem, não em fatos e resultados;

- drenar espírito empreendedor e inovador e implantar rotinas e procedimentos:

- falta de apoio da alta gerência;

- baixo grau de compiometimento nos diversos níveis hierárquicos;

- foco nos processos internos - conhecidos evisíveis - e não nos mais críticos;

- dispers̃̃o de energias e dificuldade de separar meios de fins;

- foco em padrões mínimos já existentes;

- não-alinhamento com os objetivos estratégicos;

- interferencias do ambiente;

- efeito esponja - atração de todo tipo de problema;

- conflitos de intetesse e poder, formação de grupos de evangelistas e céticos:

- benefícios intangíveis e/ou desproporcionais ao esforço;

- dificuldade em manter momentum da mudança.

Fonte: Ver notas 2 e 18. mação, Juran sugere que ela pouco difere de práticas já longamente adotadas pela função financeira das empresas. Discorda de Crosby ao não acreditar que a implantação da qualidade seja simples, mas também não crê que seja tão complexa quanto Deming propõe. Juran não atribui aos métodos estatísticos a mesma importância conferida por Deming, considerandoos ferramentas úteis, mas não fundamentais. Define qualidade como adequação ao uso - produto adequado ao uso é o que atende às necessidades de seu consumidor.

Feigenbaun originou o conceito de controle da qualidade total, tratando-o como questão estratégica que demanda profundo envolvimento de todos dentro da organização. A qualidade seria um modo de vida para as empresas, uma filosofia de compromisso com a excelência. Nesse sentido, Feigenbaun aproxima-se de Deming. Mas, pragmático, empregando a noção de custo da qualidade procurou mostrar aos administradores que os investimentos feitos em qualidade geravam retornos maiores do que os realizados em outras áreas. Deming, por sua vez, dizia que o custo da não-qualidade não pode ser conhecido. $O$ pensamento de Feigenbaun está condensado em Dezenove passos para mclhoria da qualidade. Total Quality Control ${ }^{13}$ é sua principal publicação.

Ishikawa criou os famosos círculos de controle da qualidade. Além dos CCQ, as Sete ferramentas de Ishikawa constituem importante instrumental de auxílio nos processos de controle da qualidade. Ao contrário de outras metodologias, que colocam a qualidade nas mãos de especialistas, Ishikawa acreditava que as sete técnicas podiam ser utilizadas por qualquer trabalhador. Ishikawa redefiniu o conceito de cliente, para incluir qualquer funcionário que recebe como insumo os resultados do trabalho executado anteriormente por um colega. Seu pensamento está exposto em What is lotal quality control? ${ }^{14}$.

\section{O CENÁRIO ATUAL: ESGOTAMENTO E TRANSFORMAÇÃO DO MODELO}

A prática do TQM vive um momento delicado. Evidências práticas demonstram uma lacuna entre as expectativas geradas pelos projetos de implantação e os resultados efetivamente alcançados. Ecos de descontentamento são ouvidos por todo lugar. Pesquisas indicam que dois terços dos gerentes consideram insuficientes os resultados alcançados. Um sinal de decadência, na visão de alguns autores, ć o declínio no número de inscrições para o prêmio Malcolm Baldrige, nos EUA.

Davis ${ }^{15}$, falando justamente dos premiados, concorda que o TQM vive tempos difíceis e que o entusiasmo dos anos 80 está dando lugar a dúvidas e ceticismo. $O$ essencial, para ele, é procurar integrar qualidade, estratégia e o gerenciamento financeiro da empresa.

Segundo Jacob ${ }^{16}$, se existem culpados pelas dificuldades do TQM, estes são os
13. FEIGENBAUN, Armand V. Total Quality Control. New York: McGraw-Hill, 1988.

14. ISHIKAWA, Kaoru. What is total quality control? The Japanese way. Englewood Cliffs: Prentice Hail, 1985. 215 p.

15. DAVIS, Tim R. V. Baldrige winners link quality, strategy, and financial management (5th annual total quality conference). Planning Review, Oxford, OH., v. 20 , n. 6, o. 36-40, Nov./Dec. 1992.

16. JACOB, Rahul. TOM: more than a dying fad? Fortune, New York, v. 128 , n. 9, p. 52-4, Oct. 181993. 
POR QUE

ANUNCIAR EM

UMA REVISTA

QUE QUASE SÓ

TEM TEXTOS E

NENHUMA

FOTO? 


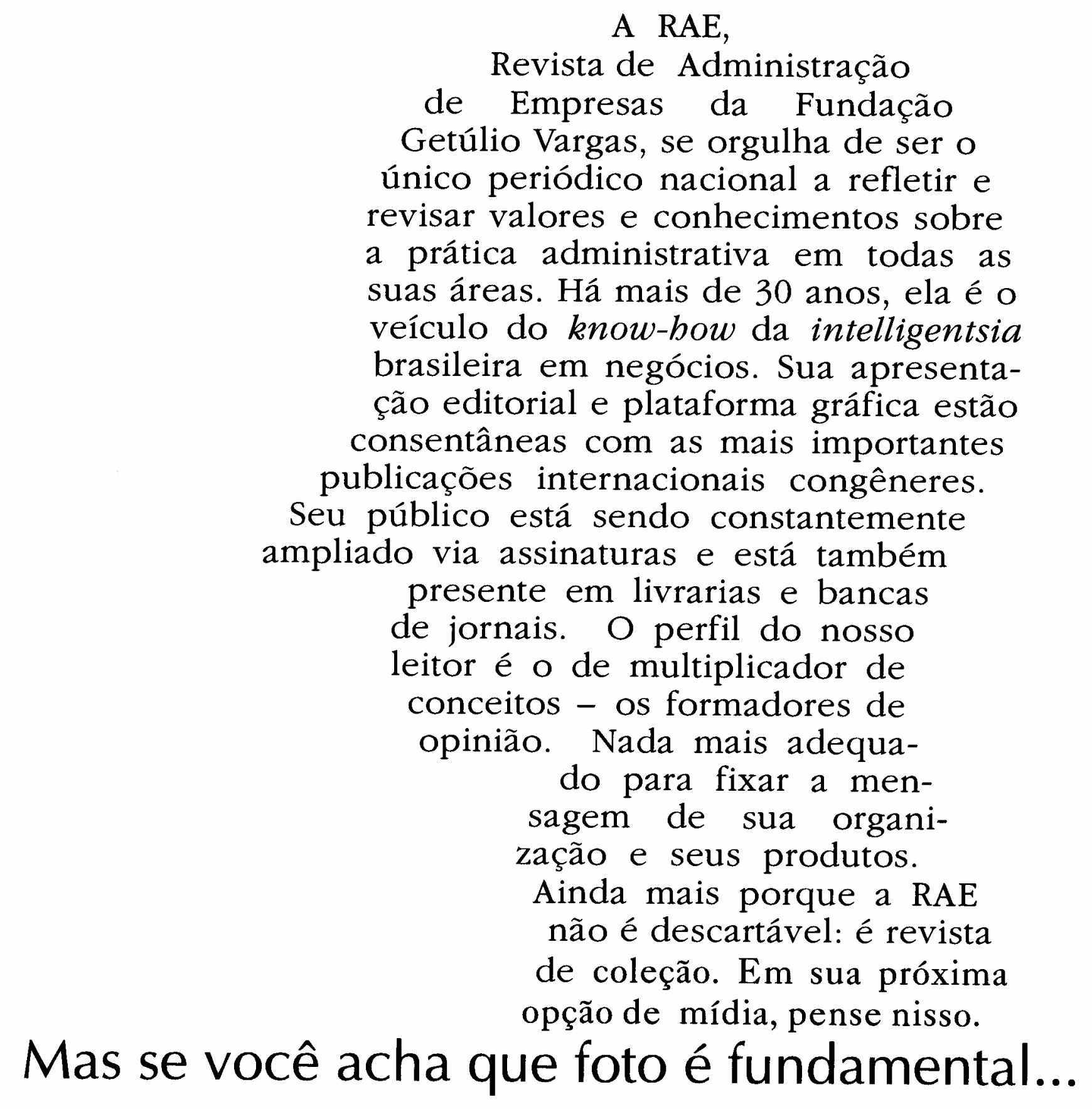

\section{A RAE light é a solução.}

RAE e RAE Light a solução em mídia com ou sem fotos. 


\section{Quadro 3 \\ TQM: algumas soluções para problemas de aplicação}

- participação efetiva do presidente da empresa;

- foco no consumidor para evitar confusão entre meios e fïns;

- ligação dos objetivos do TQM com os objetivos estratégicos da empresa, definidos de forma clara e bem divulgados;

- uso intensivo de benchmarking - comparação com os melhores;

- entendimento e atendimento das necessidades dos diversos stakeholders - atores organizacionais;

- atenção prioritánia aos processos ctíticos, que geram majores impactos;

- ligação do sistema de recompensa aos objetivos organizacionais e do programa de TQM.

Fonte: Ver notas 16 e 22.

17. MALONE, Jòhn. Creating an atmosphere of complete employee involvement in TOM (International Quality Study by American Quality Foundation and Ernst \& Young). Healthcare Financlal Management. Westchester, v. 48, n. 6, p. 1267. June 1993

18. WILSON, David C. A strategy of change: concepts and controversies in the management of change. Lundon: Routledge, $1992.147 \mathrm{o}$.

19. HARARI, Oren. Op. cit.

20. JACOB, Rahul. Op. cit.

21. JURAN, Joseph M. Made in U.S.A.: a renaissance in quality (including authar's experiences as consultant to oost-WW II Japanese manufacturers). Harvard Business Review, Boston v. 71, n. 4, p. 42-7, July/Aug. 1993.

22. ERICKSON Tamara J Beyond TOM: creating the high performance business. Management Review, Saranac Lake, v. 81, n. 7, p. 58-61, July 1992.

\section{BECKER, Selwyn W. Op. cit.}

24. CHANG, Richard $Y$, When TOM goes nowhere. Training and Development, Alexandria, Va., v. 47, p. 22-9, Jan. 1993

25. RUSSEL, John. Are we falling out of love with TQM? Electronic Business, Denver, v. 18 , p. 158 , Oct. 1992

26. DAVIS, Tim R. V. Op. cit. próprios gerentes, por sua crença em soluções mágicas e postura acrítica. Para o autor, empresas que tiveram sucesso real nas implantações incorporaram os princípios aos processos organizacionais, evitando estruturas paralelas.

Malone ${ }^{17}$ cita pesquisa da Ernst \& Young em quatro setores industriais do Canadá, Alemanha, Japão e Estados Unidos, examinando práticas gerenciais em mais de nar quais tinham real impacto no desempenho organizacional. Em geral, constatou-se que aquelas ligadas à qualidade têm impacto positivo sobre as empresas de baixo desempenho, não se constatando o mesmo efeito nas de alto desempenho. De forma geral, o estudo mostra que existem poucas verdades fundamentais e que as melhores práticas saem da adequação à realidade e ao momento da organização.

Wilson ${ }^{18}$ e Harari $^{19}$ alertam para os erros e problemas mais comuns enfrentados em aplicações de TQM. Uma síntese é apresentada no quadro 2.

Analisando o quadro 2 , observa-se que as críticas dividem-se em dois blocos: o primeiro refere-se a problemas de implantação que ocorrem na prática quando a introdução dos programas de TQM não segue o receituário e princípios adequados; o segundo refere-se a problemas mais crônicos, de concepção e características intrínsecas do TQM. Para as dificuldades do primeiro grupo e parte do segundo, Ja$\operatorname{cob}^{20}$, Juran ${ }^{21}$ e Erickson ${ }^{22}$ propõem algumas soluções, sintetizadas no quadro 3 .

A despeito do volume significativo de ressalvas partindo de diversas fontes, é necessário apontar os argumentos apre500 organizações. O objetivo foi determi- sentados em favor do TQM. Becker ${ }^{23}$ elabora longo raciocínio para provar que não existe nada intrinsecamente errado com a filosofia e os princípios do TQM. Os insucessos reportados devem-se a falhas na implementaçäo ou a programas cujo único vínculo com TQM é a denominação.

Em marcante contraste com o estudo da Ernst \& Young, Chang ${ }^{24}$ comenta pesquisa, conduzida em 84 firmas americanas, segundo a qual entre empresas onde existem programas de TQM há mais de três años, 65\% melhoraram os resultados operacionais, 69\% obtiveram maiores índices de satisfação e retenção de clientes e $53 \%$ conseguiram melhorar o clima organizacional.

Russel $^{25}$ pondera que, apesar das críticas e da falta de evidências claras quanto ao retorno financeiro proporcionado pelos programas de TQM, os EUA têm obtido considerável progresso na melhoria da qualidade de seus produtos e organizações. A redução na ênfase colocada no TQM seria um grande erro, justamente agora que a reputação dos bens produzidos naquele país começa a melhorar.

Davis $^{26}$ cita ainda os pontos comuns dos ganhadores do prêmio Malcolm Baldrige que constituem indicadores da implantação bem-sucedida do TQM. Além da maioria dos itens citados anteriormente, são mencionados: parceria com fornecedores e clientes, empowerment da força de trabalho, sistemas de medição desenvolvidos especificamente para cada negócio e adequação cultural - ou seja, valores partithados e sintonizados com os objetivos do programa

Como pode ser visto, a maior parte das críticas observadas diz respeito a dificuldades operacionais na aplicação. Fica patente, todavia, que o movimento vive momento de questionamento e certo declínio.

Em termos de transformação, algumas tendências podem ser identificadas: incorporação das práticas ao dia-a-dia das empresas; redução ou desaparecimento das estruturas paralelas, criadas para apoiar as implantações; foco nas questões relacionadas à organização do trabalho, como autonomia, participação, processo decisório, sistemas de recompensa etc.; alinhamento com objetivos estratégicos da empresa e assimilação dos conceitos e linguagem por toda a organizaçāo. 


\section{Quadro 4 \\ TQM e Reengenharia: integração}

Diferenças

- REE busca mudanças radicais e ganhos ambiciosos. TQM busca mudanças thcrementais;

- TQM parte do processo tal como ele é. REE parte de uma folha en branco;

- REE é implantada top to down. TQM tendé-a ser mais participativo;

- TQM tenta minimizar variaçóes. REE loøgliza fontes de variação para criar mudanças.

Similaridades

- ambas vêem os processos como unidade de análise:

- tanto TQM quanto REE exigen mediçöes;

- as duas abordagens implicam e necessiţam de mudanças significativas de comportamento.

Gainhos da integração

- maior orientação para resultados da REE compensaria a fraqueza do TQM nesse aspecto;

- maior apoio da alta gerência à REE poderia ser capitalizado:

- experiência e conhecimento dos profissionais de TQM em relação à análise e mediçắo de processos poderiarn sér utilizadós;

- ferramentas de TQM seriam úteis para entender e melhorar processoś existentes no curto prazo;

- o trabalho de estabilização dos processos - via TQM - poderia ser feìto após as mudanças radicais - via REE.

\section{REENGENHARIA: UM FALSO DESAFI0?}

Tornou-se usual contrapor TQM à reengenharia, considerando-se a primeira como superada em função da maior capacidade de impacto causado pela segunda.

Hammer e Champy ${ }^{27}$ colaboram para a polêmica, optando pelo estilo contundente em seu best seller Reengineering the corporation: a manifesto for business revolution. Os autores comparam-se a ninguém menos que Adam Smith e prometem uma forma totalmente nova de funcionamento para as empresas. Talvez não seja tão fácil.

Davenport ${ }^{28}$, numa posição mais conci liatória, apresenta o seguinte argumento: se, nos anos 80, as empresas mais avançadas adotaram processos de melhoria contínua (ou seja, um dos elementos básicos do TQM), nos anos 90, muitas dessas mesmas empresas estão tentando mudanças mais radicais e adotando processos de redesenho com base em reengenharia REE. Sua conclusão é que ambos podem ser integrados num programa coerente de mudança. $\mathrm{O}$ quadro 4 mostra as principais diferenças e similaridades dos dois processos e os ganhos da integração.

O autor propõe ainda que a integração seja realizada através de quatro abordagens: a primeira, por meio de um ciclo alternando inovação (mudança radical) e melhoria (mudança incremental); a se- gunda, criando-se portfolios de processos, com identificação e análise dos processos principais e adequação do tipo de mudança às necessidades de cada um; a terceira, modulando-se o grau de participação a cada nível hierárquico, com o balanceamento inteligente das características apa rentemente antagônicas da REE e do TQM; a última, combinando-se as duas metodologias para obter um compromisso de resultados de curto e longo prazo, de forma a permitir melhorias de performance consistentes e qualitativamente interessantes.

Além dos aspectos apontados por Davenport, outros são também compartilhados pelo TQM e pela REE: ambas atingiram notoriedade, o que facilita seu emprego nas organizaçōes; a aparente simplicidade e os grandes benefícios alardeados, factíveis ou não, aumentam sua atratividade junto aos gerentes em busca de soluções descomplicadas para seus problemas; ambas implicam esforços de mudança organizacional, mas são limitadas ao não tomarem em consideração, pelo menos explicitamente, elementos culturais, interações sociais e relaçōes com o ambiente.

Então, a verdadeira questão não é a da exclusão, mas a da integração e da aplicação combinadas. É o que deve acontecer à maioria das empresas, onde geralmente se adota um amálgama de sistemas e metodologias.

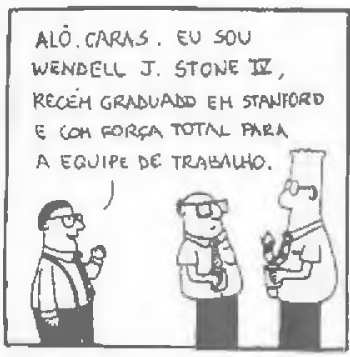

OLHA. "WEN-DULL", NO'S NAD FICAMOS IMPRESSIONA. DNS COM A SUA FORMAEÁO. NESTA COMPANITIA Ë A QUALABADE DO TRABAMTO que venta.
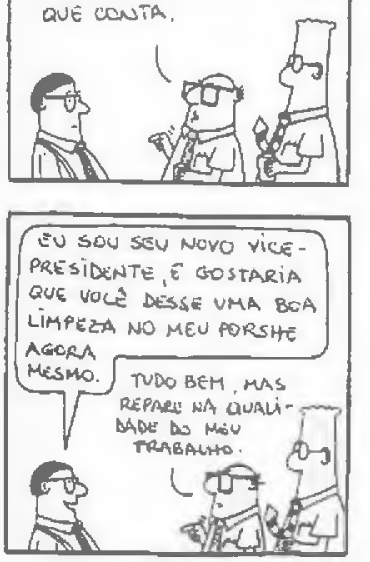

27. HAMMER, Michael, CHAMPY, James. Reengenharia: revolucionando a empresa em função dos clientes, da concorrência e das grandes mudanças da gerência. Rio de Janeiro: Ed. Campus, 1993. 189 p.

28. DAVENPORT, Thomas H. Need radical innovation and continuous improvement? Integrate process reengineering and TQM. Planning Review, Oxford, $\mathrm{OH}$., v. 22, п. 3, p. 612. May/June 1993. 
29. SHIPMAN, Alan. Quality defects (TQM vs ISO 9000 standards). International Management (Europe edition), London, v. 48, n. 4, p. 58-9, May 1993.

30. VAN NULAND, Yves. The new common language for 12 countries. Quality Progress, Milwaukee, v. 23, n. 6, p. 40-1, June 1990.

31. GALLO, Rita. Economia globalizada exige qualidade permanente em todos os produtos. Diário Comércio \& Indústria, São Paulo, 21 jan. 1993. p. 1.

32. KALINOSKY, Ian S. The total quality system - going beyond ISO 9000. Quality Progress, Milwaukee, v. 23, n. 6 , p. 50-4, June 1990 .

\section{O SISTEMA ISO 9000}

A adoção das normas ISO tem crescido, especialmente na União Européia, onde muitas empresas passaram a exigir o certificado ISO de seus fornecedores. Shipman ${ }^{29}$ aponta a implantação das normas ISO como alternativa para o TQM, cujos resultados estão sendo considerados decepcionantes.

Numa edição especial com o título World quality: making connections through standards, a revista Quality Progress ${ }^{30}$ define as normas ISO através de uma analogia: "imagine a indústria mundial como uma placa de memória de um computador e cada indústria nacional como parte da placa. Os Estados Unidos poderiam ser um chip; o Canadá, um processador; 0 Reino Unido, um capacitor, e assim por diante. Cada parte teria sido projetada para uma certa finalidade. Mas, para trabalharem juntas, as peças precisariam estar adequadamente conectadas à placa e umas às outras. Sem as devidas conexões, a placa não passa de um monte inútil de peças. Na indústria, essas conexões derivam dos padrões".

A série ISO 9000 (composta de cinco normas: ISO 9000 , ISO 9001, ISO 9002 , ISO 9003 e ISO 9004) foi desenvolvida pelo Comitê Técnico 176 da International Standards Organization (ISO) e aprovada na sua primeira versão em 1987, vindo ocupar o lugar de uma profusão de sistemas criados por empresas ou associações.

No mundo, em 1993, já eram mais de vinte mil as empresas certificadas. No Brasil, o número chegava a uma centena. Num suplemento especial da Gazeta Mercantil ${ }^{31}$, empresas operando no Brasil contam como conseguiram o certificado. Atualmente as normas ISO passam por uma atualização, cujos principais objetivos são: refletir a experiência das empresas e as melhores práticas existentes (benchmarking) e adequálas a organizações de qualquer porte.
Do ponto de vista da aplicação, alguns críticos vêem riscos de as normas ISO prenderem as empresas a padrões inferiores, ignorando mudanças ambientais, institucionalizando procedimentos que não agregam valor, fossilizando práticas e negligenciando o imperativo da melhoria contínua. Kallinosky ${ }^{32}$ contrapõe-se a essa posição, acreditando que as normas ISO podem servir de base para um sistema de qualidade total. No modelo que sugere, $o$ autor integra a essa base elementos competitivos, tecnológicos, comportamentais e organizacionais, criando uma pirâmide da qualidade.

As normas ISO constituem denominador comum de boas maneiras industriais voltadas para a qualidade. Por si só não garantem qualidade qu competitividade, mas podem servir de guia para implantação de sistemas. Uma crítica possível é que as normas ISO se assentam sobre um paradigma organizacional superado, fundado em normas e procedimentos documentados. Assim, organizações com tendências burocráticas tendem a criar camisas-de-força através das normas. Por outro lado, empresas que necessitem de um mínimo de estruturação podem encontrar na norma um guia adequado. Teoricamente, é possível fazer uma leitura não-ortodoxa da norma, evitando os riscos de rigidez e inibição da inovação através do desenvolvimento de um modelo sob medida para as necessidades estratégicas da empresa. De qualquer forma, a questão essencial parece ser a exigência de sua adoção pelos clientes. Contra esse imperativo, é difícil encontrar argumentos.

\section{TQM NO BRASIL}

Não é preciso ir além do senso comum de consumidor para constatar que, em sua grande parte, os produtos e serviços bra- 
sileiros não atingem padrões internacionais de qualidade. Da análise do setor público ao privado, de pequenas a grandes empresas, de companhias nacionais a transnacionais, obtém-se um quadro pouco animador. Mas a situação já foi pior. Segundo o Inmetro, em 1990, o índice de refugo em manufaturas brasileiras chegava a ser mais de cem vezes superior ao norte-americano ou europeu e mais de mil vezes superior ao japonês. Pesquisa da mesma época, realizada pela Êrnst \& Young-Sotec, comparava índices dà indústria nacional com parâmetros de manufaturas classe mundial aquelas que, sem distinção de origem, eram as melhores do mundo em sua indústria. Quase todos os índices de desempenho mostravam o longo caminho a percorrer até atingirmos níveis razoáveis de competitividade. A mesma pesquisa revelava, segundo visão dos empresários, os grandes obstáculos a serem vencidos. Três deles se destacavam: insuficiência de fundos para investimentos em tecnologia e treinamento, em razão de instabilidade política e econômica, altos custos de importação e mercado protegido; cultura inadequada, conservadorismo e visões ultrapassadas do próprio empresariado e falta de empenho da mão-de-obra; e falta de conhecimento técnico e administrativo.

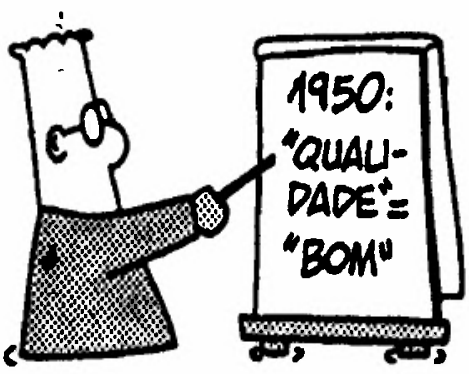

nejamento em função da instabilidade econômica, falta de treinamento dos funcionários e cultura inadequada como grandes obstáculos aos esforços pela qualidade. Empresas e empresários são também criticados por consultores e profissionais da área. Moura Estevão, do Comitê Brasileiro da Qualidade, declarou que "muitas empresas usam os programas de qualidade total como ferramenta de marketing, mas poucas estão convencidas de que seja um investimento lucrativo"35. Para Schettino Mattos, da Andersen Consulting, três fatores atrapalham a implantação dos programas: a falta de comprometimento da alta direção, a confusão entre qualidade e treinamento e a resistência dos níveis gerenciais mé$\operatorname{dios}^{36}$.

\section{APLICAÇÕES NÃO-INDUSTRIAIS DO TQM}

Para alguns estudiosos, grande parte do trabalho desenvolvido pelos mestres da qualidade, base dos programas de TQM, esteve vinculado ao contexto da produção de bens manufaturados. Rosander ${ }^{37}$ lembra que Shewhart desenvolveu os conceitos e as técnicas de inspeção da qualidade para controlar as dimensões de produtos; tratava-se de um problema de engenharia equacionado pela aplicação de estaNos últimos anos, o quadro econômico sofreu profundas alterações. Instabilidade econômica, falta de política industrial e problemas com a formação básica persistiram. Por outro lado, a redução de alíquotas de importação colocou importantes segmentos industriais diante de ameaças concretas e imediatas. Ao mesmo tempo permitiu, pelo menos potencialmente, uma atualização tecnológica das empresas. Qualidade e custos passaram a ser objeto de atenção redobrada.

Em 1992, pesquisa da Confederação Nacional da Indústria - CNI - revelava que $68 \%$ das grandes companhias nacionais já atingiam elevado grau de uso de tecnologias para aumentar a qualidade $e$ produtividade $^{33}$. Pesquisa da Price Waterhouse, pouco posterior à da CNI, mostrava que $61 \%$ das maiores firmas tinham programas de qualidade implantados ${ }^{34}$. Ambas mencionavam dificuldades de pla- tística e probabilidades. Ainda segundo Rosander, a premissa de que a qualidade de produtos e serviços são similares, implícita nos programas de TQM, conduz à crença, refutada pela experiência acumulada nos últimos 40 anos, de que a segunda pode ser satisfatoriamente equacionada apenas com instrumental fornecido por aquelas duas disciplinas.

Para um grande número de autores Albrecht e Bradford ${ }^{38}$, Berry e Parasuraman $^{39}$, Gronroos ${ }^{40}$, Heskett et al..$^{41}$ e Rosan$\operatorname{der}^{42}$, em virtude das características distinguindo bens e serviços, a compreensão e a gestão eficaz da qualidade de serviços dependem de conceitos adicionais àqueles desenvolvidos e aplicados a produtos. Como os programas de TQM geralmente não fazem referência a tais características, parece residir aí uma limitação. A despeito de tais considerações, é grande o interesse na aplicação do TQM ao setor serviços.
33. REIS, Cléber Cabral. Pesquisa da CNI revela o empenho das empresas em aumentar qualidade. Diário Comércio \& Indústria, São Paulo, 11 nov. 1992. p. 7 .

34. ZAHAR, Cristina. Economia instável atrasa programas de qualidade. Folha de $S$. Paulo São Paulo, 25 mar. 1993. p. 2-1.

35. IZIDORO, Marina. Cresce interesse pela qualidade. O Estado de S. Paulo, São Paulo, 19 abr. 1993. p.4

36. ZAHAR, Cristina. Op. cit.

37. ROSANDER, Arlyn C. Applications of quallty control in the service Industry. Milwaukee: American Society for Quality Control, 1985. $387 \mathrm{p}$.

38. ALBRECHT, Karl, BRADFORD, Lawrence J. Servicos com qualidade. São Paulo: Makron, 1992. $216 \mathrm{p}$.

39. BERRY, Leonard L, PARASURAMAN, A. Marketing services: compet/ng through quaIity. New York: The Free Press, 1991. $212 \mathrm{p}$.

40. GRONROOS, Christian. Service Management and Marketing. Lexington: Lexington Books, 1990. $298 \mathrm{p}$.

41. HESKETT, James L., SASSER, W. Earl, HART, Christopher W. L. Service breakthrougs: changing the rules of the game. New York: The Free Press, $1990.306 \mathrm{p}$.

42. ROSANDER, Arlyn C. Op cit. 
43. ZABLOKI, Elaine. Quality management targets health care (TOM applied to running a hospital). Nations's Business, v. 81, p. 40+, Feb. 1993

44. FEIGENBAUN, Armand V. TQM: health care can learn from other fields. Hospitals, v. 66, $p$. 56, Nov. 1992.

45. GEBER, Beverly. Can TOM cure health care? Training, Minneapolis, v. 29, p. 25-34, Aug. 1992.

46. HYDE, Albert $C$. The proverbs of total quality management: recharting the path to quality improvement in the public sector. Public Productivity \& Management Review, San Francisco, v. 16, p. 25-37, Fall 1992.

47. STUPAK, Ronald J. Driving forces for quality improvement in the 1990s (public sector). Public Manager, v. 22, p. 32t, Spring 1993

48. KLINE, James F. State governments' growing gains from TQM. National Productivity Review, New York, v. 12, p. 25971, Spring 1993.

49. SWISS, James E. Adapting total quaility management (TQM) to government. Public Administration Review, Washington, D.C., v. 52, p. 356-62, July/Aug. 1992.
Zabloki ${ }^{43}$ nota que as técnicas de gerenciamento da qualidade estão sendo finalmente empregadas em hospitais, com resultados encorajadores. Como parte significativa dos gastos com assistência médica derivam de desperdícios e ineficiências, a aplicação do TQM pode gerar no setor hospitalar benefícios maiores do que os obtidos em outras indústrias. Feigenbaun $^{44}$, discutindo a qualidade nos serviços de saúde, recomenda aos seus administradores que aprendam sobre a importância do TQM a partir da experiência acumulada em outros setores. Gerber ${ }^{45}$ alerta que, apesar do TQM ter ajudado, em alguns casos, a reduzir desperdícios, ineficiências e erros, muitos profissionais da área de saúde estão insatisfeitos com os efeitos na melhoria da assistência aos pacientes. Somente hospitais que aliarem baixo custo e melhor tratamento ao doente irão prosperar.

Numa época de déficits orçamentários e escassez de recursos, aumenta a consciência nos administradores do setor governo, da necessidade de mudanças e melhoria dos serviços públicos. Hyde ${ }^{46}$ destaca que a administração da qualidade despertou grande interesse em diversos níveis do setor público americano na década passada, mas observa existirem reais preocupações se o TQM constitui modis- mo ou genuíno movimento de reforma. $\mathrm{O}$ autor aponta ainda seis dimensōes para exame antes de se aplicar TQM ao setor público. Stupak ${ }^{47}$ lembra que no passado muitos estudiosos consideravam a filosofia TQM incompatível com as organizaçōes públicas. Mas isto tem mudado em decorrência de importantes demandas: aumento de produtividade, envolvimento do usuário, atribuição de maior poder decisório aos funcionários, necessidade de medir e divulgar o desempenho e desenvolver planos estratégicos de longo prazo. Similarmente, Kline ${ }^{48}$ vê na adoção do TQM por mais de cem governos municipais e doze estaduais uma resposta aos anseios dos contribuintes para que os funcionários públicos modifiquem sua filosofia e abordagem administrativas. Segundo Swiss $^{49}$, os métodos do TQM utilizados pelo setor privado podem contribuir na administração pública, mas apenas se forem substancialmente adaptados às circunstâncias únicas do contexto governamental.

Pressionadas por empresas insatisfeitas, para as quais os profissionais recém-formados estão cada vez menos preparados para trabalhar num ambiente de negócios cada vez mais hostil e complexo, diversas universidades americanas passaram a oferecer disciplinas sobre TQM nos cursos de 
Administração. Entre elas, incluem-se Michigan, Chicago, Carnegie-Mellon, Columbia, Cornell e Duke ${ }^{50}$. Mesmo assim, menos de $5 \%$ das 600 escolas americanas de Administração estão comprometidas nesse movimento. Na visão de Froilland, o principal obstáculo à introdução do TQM na academia reside na postura dos docentes, que prezam sua independência e tendem a valorizar idéias individuais em detrimento do pensamento grupal. Para Feigenbau $^{51}$, o sistema educacional americano ainda não percebeu, ao contrário de países como Alemanha e Japão, que a melhoria da qualidade representa um corpo de conhecimentos muito mais profundo do que o ensino de procedimentos estatísticos, técnicas motivacionais e relatos anedóticos de experiências bem-sucedidas. Bonser $^{52}$ articula interessante raciocínio sobre o emprego dos princípios do TQM para revitalizar o sistema e as práticas administrativas do ensino superior nos EUA. No Brasil, praticamente não há informações sobre esforços desse tipo. Existe, entretanto, a iniciativa da EAESP/FGV, que caminha na implementação de seu Plano Diretor da Qualidade.

\section{CONCLUSÃO - GERENCIANDO POR PANACÉIAS}

As metodologias fechadas (ou pacotes), destinadas a aumentar a eficácia gerencial, são cíclicas e costumam apresentar em sua história seqüências que vão do entusiasmo da adoção em larga escala até o esgotamento e abandono. Gill e Whittle ${ }^{53}$ as denominam panacéias e acreditam que essa transitoriedade está ligada a fenômenos culturais e psicodinâmicos.

A figura 3, proposta pelos autores, mostra o possível ciclo de vida de uma panacéia. Utilizando o modelo, poderíamos dizer que abordagens como Gerenciamento por Objetivos e Desenvolvimento Organizacional estariam em fase adiantada de declínio. Já o TQM estaria numa fase adiantada de maturidade e a REE ainda na etapa de adolescência.

As panacéias fazem uso de símbolos catalisadores e usam apelo emocional para conquistar possiveis praticantes. Criam uma linguagem comum, compartilhada. Em certas fases de implantação, espalhamse histórias de sucesso, utilizam-se pará- bolas e surgem heróis. Todo esse processo só é possível porque as organizações não são unicamente moldadas pelo ambiente e por uma realidade objetiva. Líderes e grupos têm muito poder na construção de uma visão comum. A dinâmica desse processo é complexa e parece caracterizar-se pela constante necessidade de gerar novidades e operar rituais de renovação. Nesse sentido, é significativa a presença de gurus no movimento da qualidade, a qual pode estar associada à dependência acrítica de líderes patriarcais, inquestionáveis detentores da sabedoria.

Gill e Whittle consideram esse processo não-cumulativo e negativo. $O$ primeiro problema seria a necessidades de vender programas simples (turn-key) pelos consultores. Como reagiria um possível cliente diante de uma exposição cheia de condicionantes e sem sequer mencionar a solução para o seu problema? Além disso, a maior parte das organizações valoriza o status e a agressividade e não o aprendizado e a reflexão. Assim, imperam posturas anti-intelectuais e falta de rigor. Uma sugestão é que as empresas implantem na estrutura posições com o papel de exercer o espírito crítico, como a de um ombusdman, que os autores chamam de truthsayer ou organizational fool. Este seria o responsável por alertar continuamente a organização sobre as armadilhas das soluções aparentemente fáceis.

Modismos realmente parecem fazer parte do dia-a-dia das organizações. Existe procura por fórmulas mágicas, conceitos simples que condensem todo um corpo complexo de idéias. Dada a dificulda de de implementar mudanças, principalmente em grandes empresas, com intrincadas redes de poder, é fácil compreender os pacotes como uma possível via preferencial. Isto não elimina suas limitações, pois geralmente são soluções simplistas e nem sempre adequadas ao problema. De fato, o caminho seria as empresas tentarem adquirir, pelo menos em suas áreas estratégicas centrais, noções mais profundas dos mecanismos de mudança organizacional e conceitos mais avançados de gerenciamento.
50. BARRIER, Michael. Business schools, TQM, and you. Nation's Business, Washington, D.C., v. 81 , p. $60-1$, July 1993; IVANCEVICH, Daniel M., INVANCEVICH, Susan H. TQM in the classroom. Management Accounting, New York, v. 74, $n$. 4, p. 14-5, Oct. 1992; JORGENSEN, Barbara. Industry to business scholls: smarten up on TQM or else. Electronic Business, v. 18, p. 85-6+, Oct. 1992.

51. FEIGENBAUM, Armand V We can't improve American quality if we aren't teaching it. National Productivity Review, New York, v. 12, p. 139-41, Spring 1993.

52. BONSER, Charles F. Total quality education? Public Administration Review, Washington, D.C., v. 52, n. 5, p. 504-12, Sept./Oct. 1992

53. GILL, John, WHITTLE, Sue. Management by panacea: accounting for transience (cyclical nature of management by objectives, organization development and TQM). Journal of Managem Studies, Oxford, v.30, n.2, p-281-95, Mar. 1993. 